\title{
Article \\ A Membrane Reactor with Microchannels for Carbon Dioxide Reduction in Extraterrestrial Space
}

\author{
Deqiang Feng, Wenjun Jiang *, Ce Zhang, Long Li, Botao Hu, Jian Song and Wei Yao * \\ Qian Xuesen Laboratory of Space Technology, China Academy of Space Technology, 104 Youyi Road, \\ Beijing 100094, China; fengdeqiang@qxslab.cn (D.F.); zhangce@qxslab.cn (C.Z.); lilong@qxslab.cn (L.L.); \\ hubotao@qxslab.cn (B.H.); songjian@qxslab.cn (J.S.) \\ * Correspondence: wenjunjiang@qxslab.cn (W.J.); weiyao@qxslab.cn (W.Y.)
}

Citation: Feng, D.; Jiang, W.; Zhang C.; Li, L.; Hu, B.; Song, J.; Yao, W. A Membrane Reactor with

Microchannels for Carbon Dioxide Reduction in Extraterrestrial Space. Catalysts 2022, 12, 3. https://doi.org/ $10.3390 /$ catal12010003

Academic Editors: Shangqian Zhu, Qinglan Zhao and Yao Yao

Received: 19 November 2021 Accepted: 19 December 2021 Published: 21 December 2021

Publisher's Note: MDPI stays neutral with regard to jurisdictional claims in published maps and institutional affiliations.

Copyright: (C) 2021 by the authors. Licensee MDPI, Basel, Switzerland. This article is an open access article distributed under the terms and conditions of the Creative Commons Attribution (CC BY) license (https:// creativecommons.org/licenses/by/ $4.0 /)$.

\begin{abstract}
Long-term continuous oxygen supply is of vital importance during the process of space exploration. Considering the cost and feasibility, in situ resource utilization (ISRU) may be a promising solution. The conversion of $\mathrm{CO}_{2}$ to $\mathrm{O}_{2}$ is a key point for ISRU. In addition, the utilization of the abundant $\mathrm{CO}_{2}$ resources in the atmosphere of Mars is an important topic in the field of manned deep space exploration. The Sabatier reaction, Bosch reaction, and solid oxide electrolysis (SOE) are well-known techniques for the reduction of $\mathrm{CO}_{2}$. However, all the above techniques need great energy consumption. In this article, we designed an electrochemical membrane reactor at room temperature based on microfluidic control for the reduction of $\mathrm{CO}_{2}$ in extraterrestrial space. In this system, $\mathrm{H}_{2} \mathrm{O}$ was oxidized to $\mathrm{O}_{2}$ on the anode, while $\mathrm{CO}_{2}$ was reduced to $\mathrm{C}_{2} \mathrm{H}_{4}$ on the cathode. The highest Faraday efficiency (FE) for $\mathrm{C}_{2} \mathrm{H}_{4}$ was $72.7 \%$, with a single-pass carbon efficiency toward $\mathrm{C}_{2} \mathrm{H}_{4}$ (SPCE- $\mathrm{C}_{2} \mathrm{H}_{4}$ ) of $4.64 \%$. In addition, a microfluidic control technique was adopted to overcome the influence of the microgravity environment. The study may provide a solution for the long-term continuous oxygen supply during the process of space exploration.
\end{abstract}

Keywords: microchannel; carbon dioxide reduction; membrane reactor; extraterrestrial space

\section{Introduction}

In the process of manned space flight and extraterrestrial exploration, astronauts are faced with basic material and energy requirements. An astronaut consumes about $820-840 \mathrm{~g}$ of oxygen and exhales 1000-1040 g of carbon dioxide a day [1]. It is expensive and technically difficult to carry all the consumables from Earth for long-term manned extraterrestrial exploration. Therefore, extraterrestrial resources must be utilized and recycled, which could reduce the mass of consumables carried from Earth and make the manned deep space exploration missions feasible. In addition, $\mathrm{CO}_{2}$ is a metabolic product of humans, which may take a toll on health when the concentration of $\mathrm{CO}_{2}$ is greater than $4 \mathrm{mmHg}$ [2]. It is of vital importance to reduce $\mathrm{CO}_{2}$ and produce $\mathrm{O}_{2}$ and carbon fuels. Up to now, there are several technical paths to achieve this goal. The Sabatier reaction is one of the state-of-the-art $\mathrm{CO}_{2}$ reduction technologies, which has been fully operational on the International Space Station in 2011 [3]. For the Sabatier reaction, $\mathrm{CO}_{2}$ is reduced by hydrogen to generate methane and $\mathrm{H}_{2} \mathrm{O}$. Hydrogen comes from water electrolysis. Bosch reaction is another technique for $\mathrm{CO}_{2}$ reduction, in which $\mathrm{CO}_{2}$ is reduced by hydrogen to generate carbon and $\mathrm{H}_{2} \mathrm{O}$. Compared with the Sabatier reaction, the Bosch reaction theoretically allows for $100 \% \mathrm{O}_{2}$ recovery from $\mathrm{CO}_{2}$. However, carbon deposition may block the catalyst surface and reduce reaction efficiency. Solid oxide electrolysis (SOE) provides a direct path for $\mathrm{CO}_{2}$ decomposition, which could directly split $\mathrm{CO}_{2}$ into $\mathrm{O}_{2}$ and $\mathrm{CO}$ and is especially of interest for the utilization of $\mathrm{CO}_{2}$ in the Martian atmosphere $[4,5]$. The Mars Oxygen In situ Resource Utilization Experiment (MOXIE) has realized the goal of producing $\mathrm{O}_{2}$ from $\mathrm{CO}_{2}$ of the Martian atmosphere through SOE, whose oxygen production rate is $5.4 \mathrm{~g} / \mathrm{h}$. Despite the remarkable achievements of these technologies, there are also 
several obvious drawbacks. For example, hydrogen is necessary for both the Sabatier and Bosch reactions, which may be an unsafe factor for manned aircraft. Moreover, all three reactions are high-temperature reactions $\left(300-800^{\circ} \mathrm{C}\right)$, which heavily consume energy and are unsafe. Therefore, it is urgent to solve these problems through new technology.

Extraterrestrial artificial photosynthesis technology (extraterrestrial photo/electrocata lytic carbon dioxide reduction technology) is a new technology first proposed by Qian Xuesen Laboratory of Space Technology and Nanjing University, which enables the controlled conversion of carbon dioxide into oxygen and carbon-containing fuels through photo/electrocatalysis at room temperature and pressure [6]. Considering that sunlight is almost the only sustainable energy source in extraterrestrial space, the technological path of photovoltaic-electrochemical (PV-EC) may be the optimal technology path for $\mathrm{CO}_{2}$ utilization, of which zero-gap configuration or membrane electrode assembly (MEA) configuration is most likely to be put into practical application. Although a series of works related to MEA have been reported [7-14], factors related to the reactor adaptability in extraterrestrial space, such as the microgravity environment, mechanics, and airtightness requirements, are rarely considered.

Generally, the $\mathrm{CO}_{2}$ chemical reduction comprises three steps: $\mathrm{CO}_{2}$ adsorption, $\mathrm{CO}_{2}$-tohydrocarbon conversion, and reaction products separation. First, $\mathrm{CO}_{2}$ molecules adsorb on the surface of a photocatalyst; then, the electrons migrate from the bulk to the surface to reduce $\mathrm{CO}_{2}$ to hydrocarbons; lastly, the products desorb and separate from the electrode surface for the sequential reaction. Nevertheless, for the third step, the reaction products, especially gas bubbles, cover the electrode surface and cannot desorb and separate in the microgravity environment, which enlarges the ohmic resistance of the system and even terminates the reaction [15]. Recently, a new technology of microfluidics has emerged, which can leverage specific advantages in photoelectrochemical catalysis such as fine flow control and large surface-area-to-volume ratio. Owing to these features, it has shown great potential to accelerate reaction rates by improving the mass and photon transfer and, hence, has become a promising platform for catalytic reaction systems. Furthermore, the surface tension and flow shear force in the microchannel fluid reaction process could be precisely controlled by adjusting the surface morphology and flow rate to effectively promote the gas-liquid interfacial phase separation under a microgravity environment [16].

Herein, we designed a membrane reactor with microchannels for the electrocatalytic reduction of $\mathrm{CO}_{2}$ at room temperature in extraterrestrial space. Microfluidic control technique was adopted to overcome the influence of the microgravity environment. In this system, the highest Faraday efficiency (FE) of $\mathrm{C}_{2} \mathrm{H}_{4}$ was $72.7 \%$, with a current density of $88 \mathrm{~mA} / \mathrm{cm}^{2}$. The single-pass carbon efficiency (SPCE) of $\mathrm{CO}_{2}$ toward $\mathrm{C}_{2} \mathrm{H}_{4}$ and gas products were $4.64 \%$ and $11.61 \%$, respectively. In addition, the influence of cell voltage, the flow rate of electrolyte and $\mathrm{CO}_{2}$, channel structure, and membrane on the reaction are discussed in detail. The study contributes to the long-term, continuous oxygen supply during the process of space exploration.

\section{Results and Discussion}

\subsection{System and Reactor Structure}

The schematic of the extraterrestrial artificial photosynthesis system is shown in Figure 1. System components were connected using polyether ether ketone (PEEK), having an outer diameter of $3 \mathrm{~mm}$. In the microgravity environment, liquid cannot be separated effectively from gas and be driven to flow by gas in a conventional container. Thus, in the system, the anolyte was stored in a cystic electrolyte tank of which shell was fabricated with titanium alloy (Aerospace class). The anolyte pressure and flow rate were controlled by a pressure relief valve (Aerospace class). The cathodic gas pressure and flow rate were controlled using a mass-flow controller (CS200A, Beijing Sevenstar Flow Co., Ltd., Beijing, China). Both the anolyte and cathodic gas were connected to the $\mathrm{CO}_{2}$ gas cylinder, and the circulation was turned on or turned off by controlling the pressure transducers (Aerospace class), of which the on/off threshold pressure values were logged in by the computer, up- 
stream of the pressure relief valve and mass-flow controller. Two soft bags manufactured with the polyvinyl chloride (PVC) downstream of the cell were utilized to collect the anodic and cathodic reaction products. The gaseous components of the reaction products were injected into gas chromatography to analyze the gas composition. A high-resolution chargecoupled device (CCD) camera was used to observe and record the gas behavior during the reaction process.

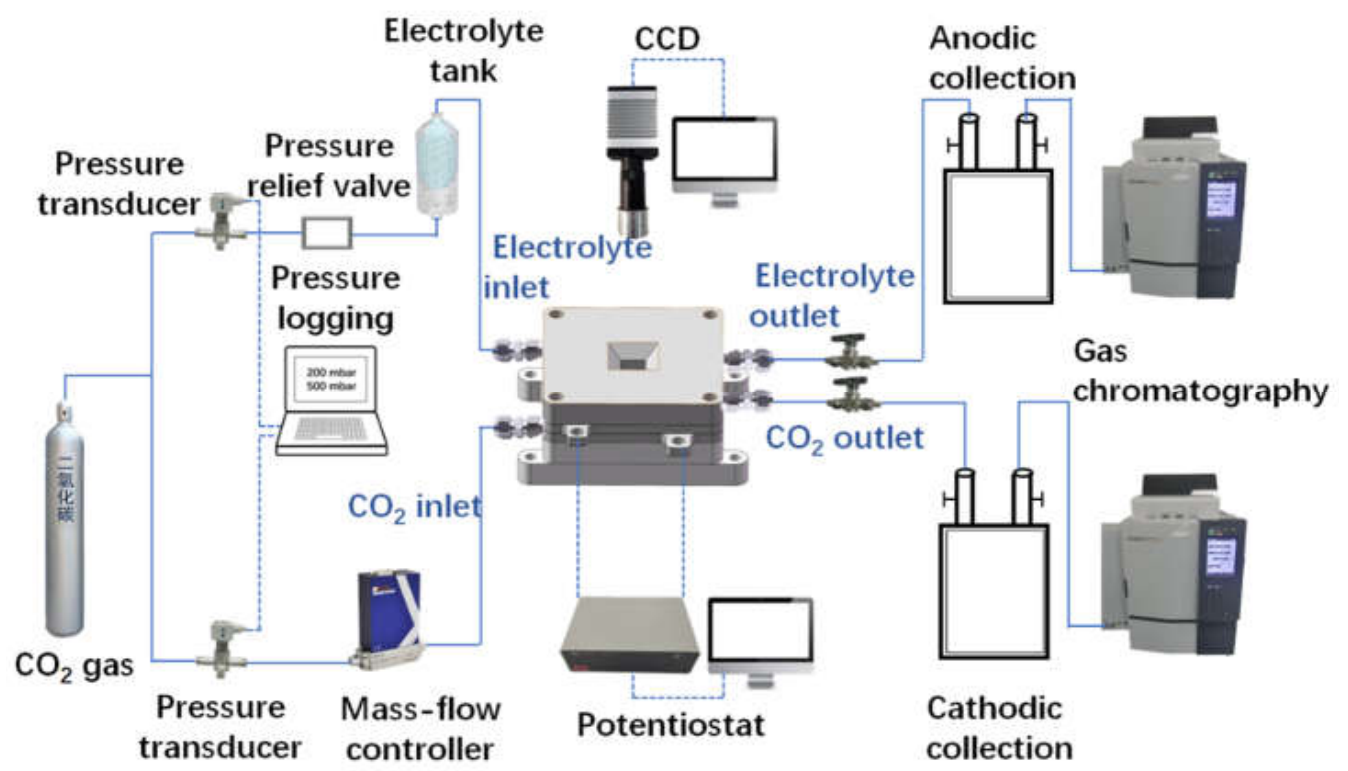

Figure 1. Schematic diagram of the extraterrestrial artificial photosynthesis system.

As shown in Figure 2, all $\mathrm{CO}_{2}$ electrochemical reduction experiments were performed in a membrane reactor with microchannels, wherein a polymer electrolyte membrane (anion exchange membrane) separates the anode from the cathode. The cathode was exposed to the $\mathrm{CO}_{2}$ gas stream on one side and the anolyte stream on the other. The $\mathrm{IrO}_{2}$ anode was completely immersed in the liquid anolyte. The cell contained four inlets and outlets, two ports for each fluid (anolyte and $\mathrm{CO}_{2}$ ). To avoid the electrochemical corrosion to the electrode substrate during the reduction process, the cell structure employed electrode substrate and collection substrate as the current collectors and reactant collectors. The anodic and cathodic substrates (current collectors) were fabricated from T4c titanium alloy, wherein the flow field in the center of the anodic substrate was fabricated from transparent polymethylmethacrylate (PMMA) to facilitate observation and recording using a CCD camera. Both flow fields of anodic and cathodic substrates have active areas of $2.5 \times 2.5 \mathrm{~cm}^{2}$. Considering the influence of microgravity on the separation of gas and liquid, a series microchannel structure and a parallel microchannel structure with a widthto-depth ratio of $600 \mu \mathrm{m}$ to $200 \mu \mathrm{m}$ were utilized during the $\mathrm{CO}_{2}$ reduction experiments. Moreover, for comparison, a series macrochannel structure with a width-to-depth ratio of $1000 \mu \mathrm{m}$ to $400 \mu \mathrm{m}$ was also investigated. The collection substrate (reactant collectors) and the fixed substrate were fabricated from aluminum metal. In addition, a window on the anodic collection substrate was formed for observation and recorded using a CCD camera. 


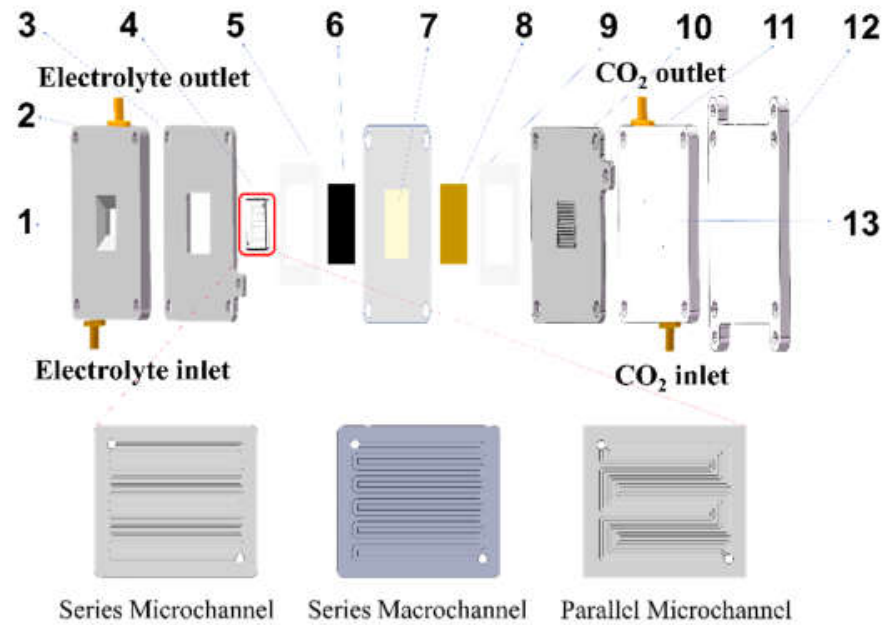

1-Observation Window, 2, 11-Anodic and Cathodic Collection Substrate, 3-Anodic Substrate, 4, 13-Anodic and Cathodic Microchannel, 5, 9-Gasket, 6-Anode, 7-Membrane, 8-Cathode, 10-Cathodic Substrate, 12-Fixed Substrate

Figure 2. Assembly drawing of the membrane reactor with microchannels.

\subsection{Morphology and Structure Characterization}

To explore the morphology of CuNWs, scanning electron microscopy (SEM) and transmission electron microscopy (TEM) were carried out. As shown in Figure $3 a, b$, the morphology of the CuNWs was ultralong nanowires, the length of which was up to around $15 \mu \mathrm{m}$. It is worth noting that there was also a small number of nanocubes. Figure $3 \mathrm{e}$ and Figure S1 show that the diameter of the CuNWs was around 20 80 nm. Figure 3c,d show the cross-sectional SEM images of the CuNW-based gas diffusion electrode. The gas diffusion electrode (GDE) was composed of the catalyst layer and gas diffusion layer. The thickness was in a range of tens to hundreds of nanometers. The CuNW-based gas diffusion electrode showed a rusty red color (Figure 3f).

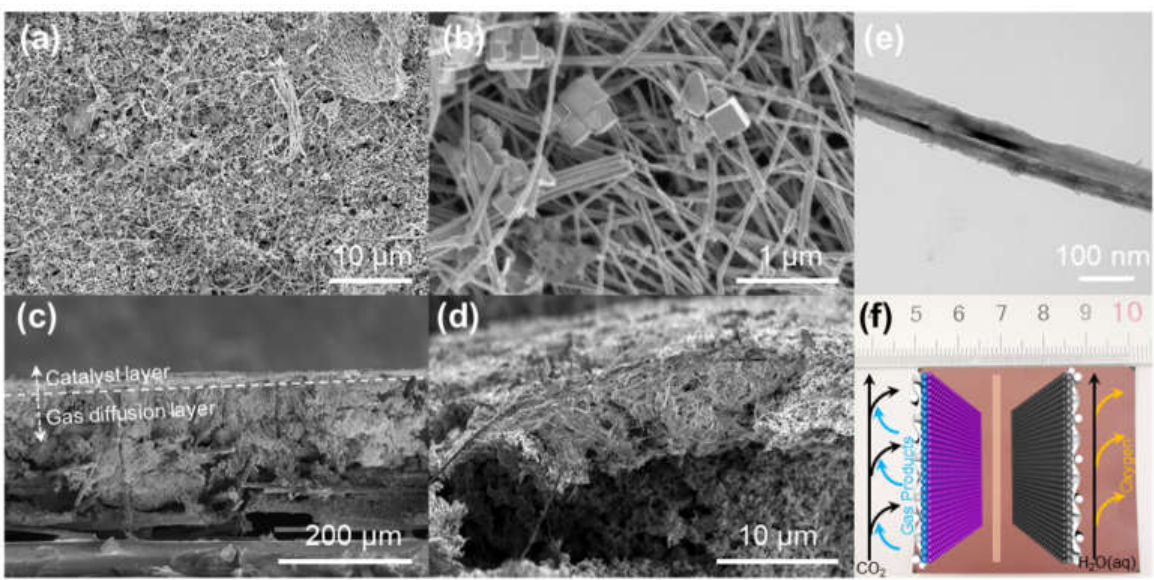

Figure 3. (a,b) SEM images and (c,d) cross-sectional SEM images of CuNW-based gas diffusion electrode; (e) TEM image of CuNWs; (f) photograph and schematic diagram of CuNW-based gas diffusion electrode.

X-ray diffraction (XRD) patterns were performed to elucidate the crystal structure of CuNWs (Figure 4). Three peaks were found at $43.3^{\circ}, 50.4^{\circ}$, and $74.1^{\circ}$ in the XRD patterns, demonstrating that $\mathrm{CuNW}$ displayed a cubic phase of copper sharing a space group of Fm-3m (JCPDS, No. 04-0836). Peaks at $26.8^{\circ}$ and $54.4^{\circ}$ were ascribed to the carbon paper substrate. 


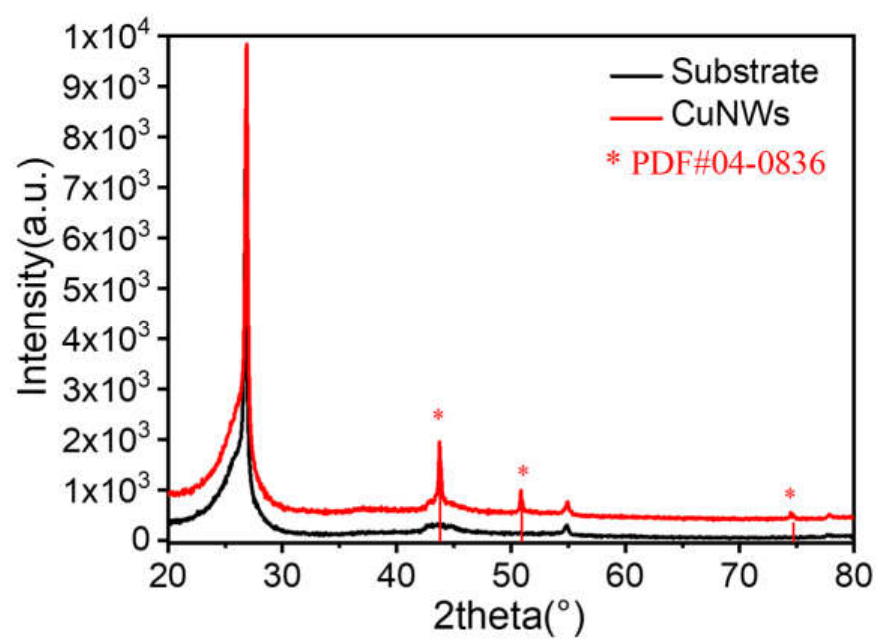

Figure 4. XRD patterns of CuNWs.

X-ray photoelectron spectra (XPS) were conducted to elucidate the surface valence of CuNWs. XPS survey spectrum showed that the samples were composed of $\mathrm{Cu}, \mathrm{O}$, and $\mathrm{C}$ elements (Figure S2). The peak at $284.8 \mathrm{eV}$ was attributed to the carbon contaminations in the high-resolution XPS spectrum of C1s (Figure 5a) [17]. For the high-resolution XPS spectrum of O1s (Figure 5b), two peaks at $531.8 \mathrm{eV}$ and $529.8 \mathrm{eV}$ were found, which were ascribed to surface adsorbed oxygen and lattice oxygen species, respectively [18]. The $\mathrm{Cu} 2 \mathrm{p}_{3 / 2}$ spectra were deconvoluted to two peaks at $934.2 \mathrm{eV}$ and $932.1 \mathrm{eV}$ (Figure $5 \mathrm{c}$ ), which were attributed to $\mathrm{Cu}$ (II) and $\mathrm{Cu}$ (I or 0), respectively [18]. It is difficult to distinguish $\mathrm{Cu}$ (I) and $\mathrm{Cu}(0)$ through $\mathrm{Cu} 2 \mathrm{p}$ since their similar energy values. As shown in Figure 5d, X-ray Auger $\mathrm{Cu}$ LMM spectra were adopted to identify $\mathrm{Cu}(\mathrm{I})$ and $\mathrm{Cu}(0)$. Two peaks were found at $918.4 \mathrm{eV}$ and $916.8 \mathrm{eV}$, which were ascribed to $\mathrm{Cu}(0)$ and $\mathrm{Cu}(\mathrm{I})$, respectively $[19,20]$. Combining the results of XRD and XPS, we can confirm that the $\mathrm{Cu}$ element on the surface was mainly in the form of $\mathrm{Cu}$ (II) and $\mathrm{Cu}$ (I), while the $\mathrm{Cu}$ element in the bulk was $\mathrm{Cu}(0)$. The possible reason could be attributed to partial oxidation of the surface by the oxygen in the atmosphere.

(a)

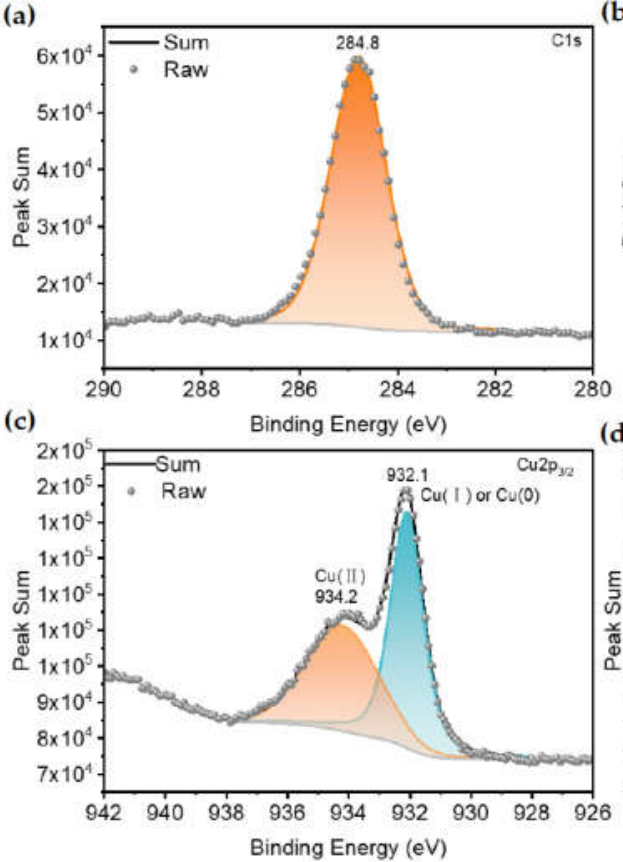

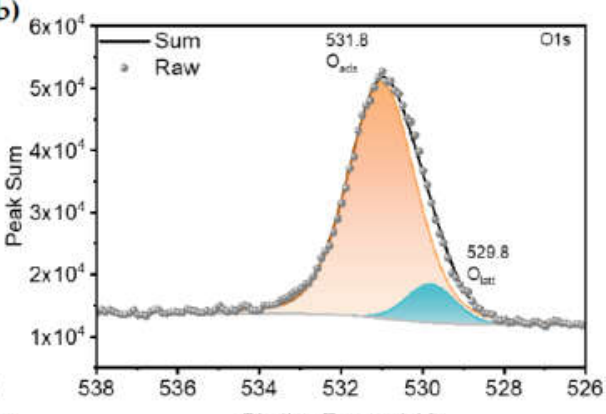

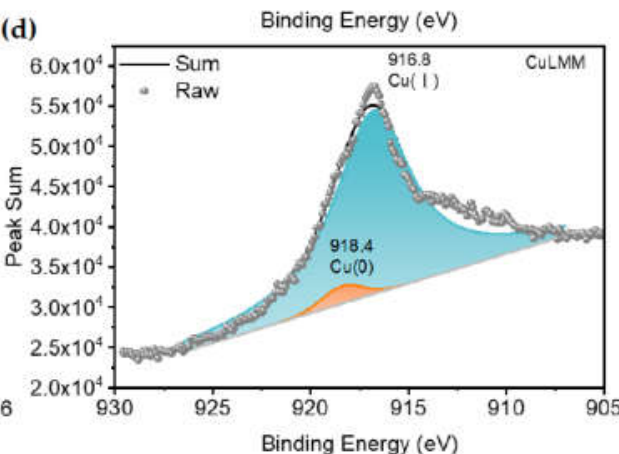

Figure 5. XPS spectra of CuNWs for (a) C1s, (b) O1s, (c) Cu2 $\mathrm{p}_{3 / 2}$ and (d) CuLLM. 


\section{3. $\mathrm{CO}_{2}$ Reduction Performance}

\subsubsection{Voltage}

$\mathrm{KOH}$ solution could provide a strong alkaline environment, which could inhibit hydrogen evolution reaction, strengthen the $\mathrm{C}-\mathrm{C}$ coupling, and promote the Faraday efficiency (FE) of $\mathrm{C}_{2} \mathrm{H}_{4}$ [21]. However, the strong alkaline environment will lead to the reaction between $\mathrm{CO}_{2}$ and $\mathrm{OH}^{-}$to form $\mathrm{CO}_{3}{ }^{2-}$, which could pass through the anion exchange membrane, resulting in cross-contamination, and dragging down the energy efficiency and raw material utilization rate [22,23]. Sargent pointed out that more than $50 \%$ of the energy used in the electroreduction of $\mathrm{CO}_{2}$ under alkaline conditions is used to recover the $\mathrm{CO}_{2}$ forming $\mathrm{CO}_{3}{ }^{2-}$ [24]. Therefore, a weak alkaline environment may be an effective method of solving this problem. Here, $0.2 \mathrm{M} \mathrm{KHCO}_{3}$ dilute solution was adopted as the electrolyte solution. As shown in Figure $6 \mathrm{a}, \mathrm{b}$, the current increased as the cell voltage increased. The current density reached about $96 \mathrm{~mA} / \mathrm{cm}^{2}$ when the cell voltage was $4.4 \mathrm{~V}$. Figure $6 \mathrm{~b}$ shows the Faraday efficiencies (FE) at different cell voltages. The FE of $\mathrm{CO}$ decreased as the cell voltage increased, while the $\mathrm{FE}$ of $\mathrm{C}_{2} \mathrm{H}_{4}$ increased as the cell voltage increased. The FEs of $\mathrm{C}_{2} \mathrm{H}_{4}$ at $4.2 \mathrm{~V}$ and $4.4 \mathrm{~V}$ were $44.2 \%$ and $44.7 \%$, respectively. The highest $\mathrm{FE}$ of all gas products for $\mathrm{CO}_{2}$ reduction $\left(\mathrm{CO}_{2} \mathrm{RR}(\mathrm{gas})\right)$ reached $61.8 \%$ at $4.2 \mathrm{~V}$.
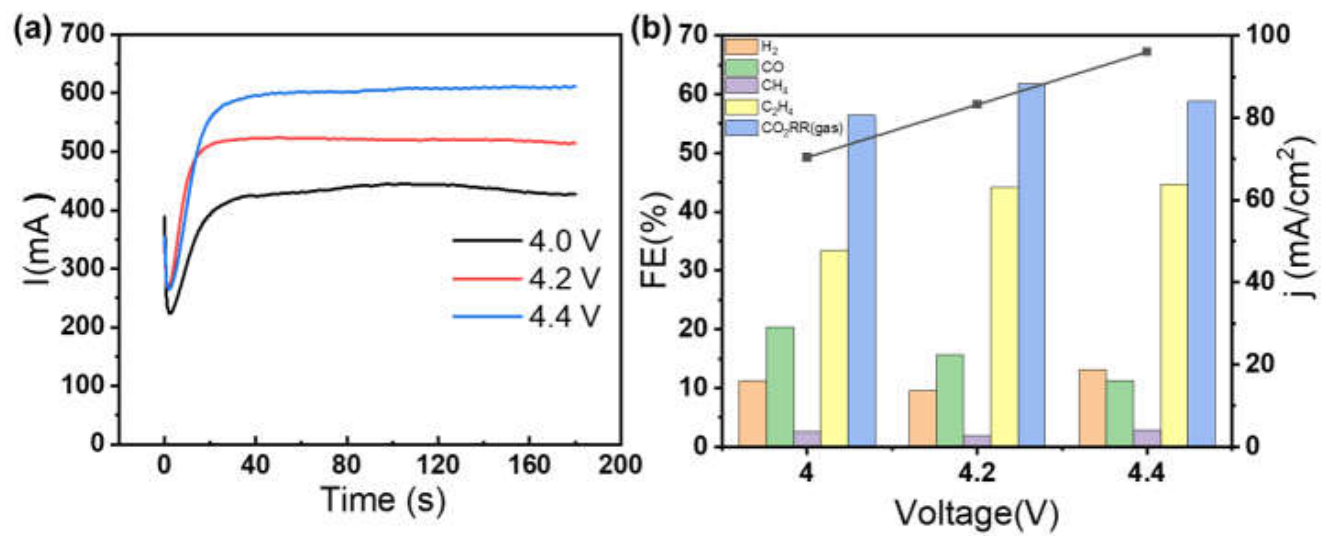

Figure 6. (a) I-t curve at different voltages; (b) the Faraday efficiency of gas products and current density at different voltages. Operating parameter: $\mathrm{CO}_{2}$ gas flow rate of $20 \mathrm{sccm}$, anolyte flow rate of $10 \mathrm{sccm}$, the anion exchange membrane of Sustainion X37-50 Grade T, and the channel type of parallel microchannel structure.

\subsubsection{Flow Rate}

Furthermore, we explored the influence of the flow rates of electrolyte and $\mathrm{CO}_{2}$ on the Faraday efficiency of gas products and current density. As shown in Figure 7a, both the FE of $\mathrm{C}_{2} \mathrm{H}_{4}$ and $\mathrm{CO}_{2} \mathrm{RR}$ (gas) increased as the electrolyte flow rate increased. In addition, the $\mathrm{FE}$ of $\mathrm{H}_{2}$ remarkably increased when the electrolyte flow rate was only $5 \mathrm{sccm}$, which may be ascribed to the bubble accumulation on the electrode surface. Low electrolyte flow rate makes it difficult for $\mathrm{O}_{2}$ bubbles produced on the electrode to desorb, which leads to higher interface resistance. This phenomenon is magnified in a microgravity environment, which has been proved by Y. Fukunaka [15]. Therefore, it is necessary to keep a relatively high electrolyte flow rate especially in microgravity environmental. However, the electrolyte flow rate cannot increase indefinitely considering the reserve of electrolytes in the cystic tank for the entire experiment in an extraterrestrial environment. As shown in Figure $7 \mathrm{~b}$, the FE of $\mathrm{CO}$ decreased as the gas flow rate decreased, while the $\mathrm{FE}$ of $\mathrm{H}_{2}$ increased as the gas flow rate decreased. The FE of $\mathrm{C}_{2} \mathrm{H}_{4}$ exhibited a peak value of $67.7 \%$ when the gas flow rate was $10 \mathrm{sccm}$. This phenomenon could be attributed to the increased retention time of ${ }^{*} \mathrm{CO}$ since a longer retention time is beneficial for $\mathrm{C}-\mathrm{C}$ coupling. On the other hand, a low gas flow rate led to low carbon dioxide flux, which is relatively favorable for hydrogen evolution reactions. Combined with the above analysis, the optimal values for electrolyte flow rate and gas flow rate were $10 \mathrm{sccm}$ and $10 \mathrm{sccm}$, respectively. 

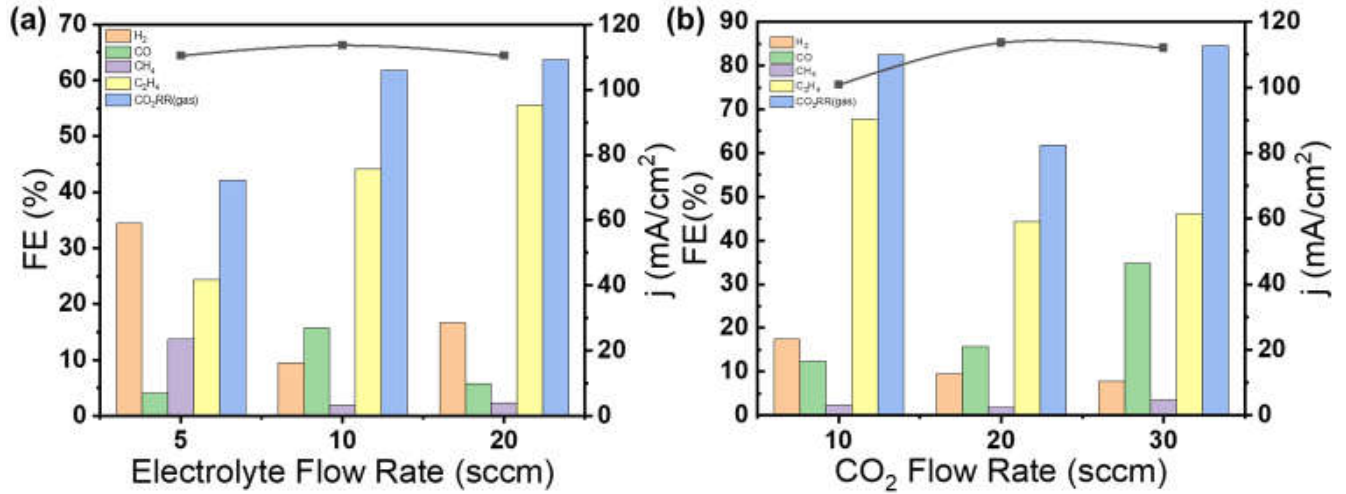

Figure 7. (a) The Faraday efficiency of gas products and current density at different electrolyte flow rates. Operating parameter: Cell voltage $4.2 \mathrm{~V}, \mathrm{CO}_{2}$ gas flow rate of $20 \mathrm{sccm}$, the anion exchange membrane of Sustainion X37-50 Grade T, and the channel type of parallel microchannel structure; (b) the Faraday efficiency of gas products and current density at different $\mathrm{CO}_{2}$ flow rates. Operating parameter: Cell voltage $4.2 \mathrm{~V}$, anolyte flow rate of $10 \mathrm{sccm}$, the anion exchange membrane of Sustainion X37-50 Grade T, and the channel type of parallel microchannel structure.

\subsubsection{Channel Structure}

Channel structure has an important influence on the distribution of the $\mathrm{CO}_{2}$ flow field [25]. We designed three types of channel structure to explore the effect of mass transfer on $\mathrm{CO}_{2}$ reduction reaction: series macrochannel, series microchannel, and parallel microchannel. As shown in Figure 8a, compared with the series macrochannel structure, in the series microchannel, the FE of CO decreased, while the $\mathrm{FE}$ of $\mathrm{H}_{2}$ and $\mathrm{C}_{2} \mathrm{H}_{4}$ increased, and the $\mathrm{FE}$ of $\mathrm{C}_{2} \mathrm{H}_{4}$ exhibited a value of $54.4 \%$. Particularly, the current density in the series microchannel structure was $88 \mathrm{~mA} / \mathrm{cm}^{2}$, which is $19.6 \%$ higher than that in the series macrochannel model. To explore the reason for the increased current density, we took the microscopy images of the bubble dynamics, shown in Figure 8b. In the series macrochannel model, the $\mathrm{O}_{2}$ bubble showed a continuous big bubble form. There were two defects in the form. Firstly, the continuous big bubble form would insulate the electrolyte from the electrode, which results in an increased interface resistance and reduced reaction current density. Second, in a microgravity environment, it is difficult for the continuous, large bubble to detach from the electrode, which will further block the reaction. On the contrary, in the series microchannel structure, the $\mathrm{O}_{2}$ bubble showed a slug flow form. The discontinuous, small bubble could be forced out by the fluid shear stress [16], which may overcome the adverse effect of microgravity on bubble detachment. Compared with the series microchannel model, in the parallel microchannel, the $\mathrm{FE}$ of $\mathrm{C}_{2} \mathrm{H}_{4}$ further increased. The FE of $\mathrm{C}_{2} \mathrm{H}_{4}$ exhibited a value of $67.7 \%$, and the corresponding current density was $100.8 \mathrm{~mA} / \mathrm{cm}^{2}$. The increased $\mathrm{C}_{2} \mathrm{H}_{4} \mathrm{FE}$ and current density may be attributed to the strengthened mass transfer of $\mathrm{CO}_{2}$ [25]. The retention time of $\mathrm{CO}_{2}$ and ${ }^{*} \mathrm{CO}$ in the parallel microchannel structure was longer than that in the series microchannel since the parallel microchannel structure holds a shorter channel length, and a longer retention time strengthens the mass transfer of $\mathrm{CO}_{2}$ for making the $\mathrm{C}-\mathrm{C}$ coupling.

\subsubsection{Membrane}

The thickness, conductivity, and composition of the membranes have important effects on the FE, current density, and even the stability of the $\mathrm{CO}_{2}$ reduction reaction [26,27]. Here, we compared three common commercial anion exchange membranes: Sustainion X37-50 Grade T ( $\sim 50 \mu \mathrm{m}$, Dioxide Materials, Boca Raton FL, USA), Sustainion X37-50 Grade $60(\sim 50 \mu \mathrm{m}$, Dioxide Materials, Boca Raton FL, USA), and Fumasep FAA-3-20 ( $\sim 20 \mu \mathrm{m}$, Fumatech BWT GmbH, Baden-Württemberg, Germany). The membrane of Sustainion X3750 Grade $\mathrm{T}$ is a sandwich structure with a thin and porous PTFE layer coated. Therefore, the mechanical property is superior. However, as shown in Figure 9, the FE of $\mathrm{C}_{2} \mathrm{H}_{4}$ using Sustainion X37-50 Grade T is smaller than that using the other two membranes. The FEs 
of $\mathrm{C}_{2} \mathrm{H}_{4}$ and $\mathrm{CO}_{2} \mathrm{RR}$ (gas) using Sustainion X37-50 Grade 60 were higher than those using FAA-3-20. The highest FE of $\mathrm{C}_{2} \mathrm{H}_{4}$ using Sustainion X37-50 Grade 60 was $72.7 \%$, with a current density of $88 \mathrm{~mA} / \mathrm{cm}^{2}$. The typical TCD and FID chromatograms of cathodic gas products were shown in Figure S3. Table S1 shows the single-pass carbon efficiency (SPCE) of $\mathrm{CO}_{2}$ in each product at 4.2 V. The SPCE- $\mathrm{C}_{2} \mathrm{H}_{4}$ and SPCE-gas using Sustainion X37-50 Grade 60 were $4.64 \%$ and $11.61 \%$, respectively. The energy efficiency (EE) of $\mathrm{CO}_{2}$ toward $\mathrm{C}_{2} \mathrm{H}_{4}$ using Sustainion X37-50 Grade 60 at $4.2 \mathrm{~V}$ was $19.9 \%$ (Table S2). Evidently, the energy efficiency was relatively low. The reason may be ascribed to the anode, which needs a relatively high overpotential for water oxidation. Subsequent optimization is required for the anode to decrease the overpotential for water oxidation and further decrease the cell voltage.

(a)

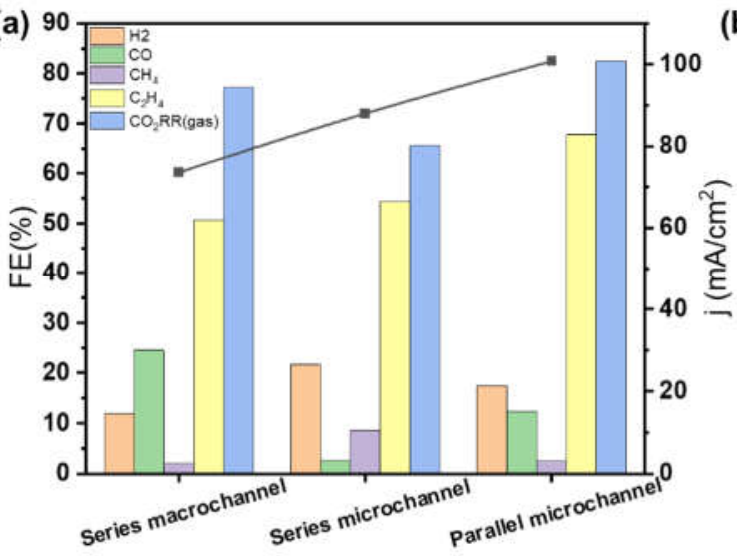

(b)
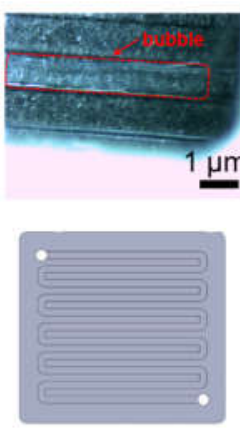

Series Macrochannel Series Microchannel

Figure 8. (a) The Faraday efficiency of gas products and current density with different channel structures; (b) microscopic images of the bubble dynamics. Operating parameter: Cell voltage $4.2 \mathrm{~V}$, $\mathrm{CO}_{2}$ gas flow rate of $10 \mathrm{sccm}$, anolyte flow rate of $10 \mathrm{sccm}$, and the anion exchange membrane of Sustainion X37-50 Grade T.

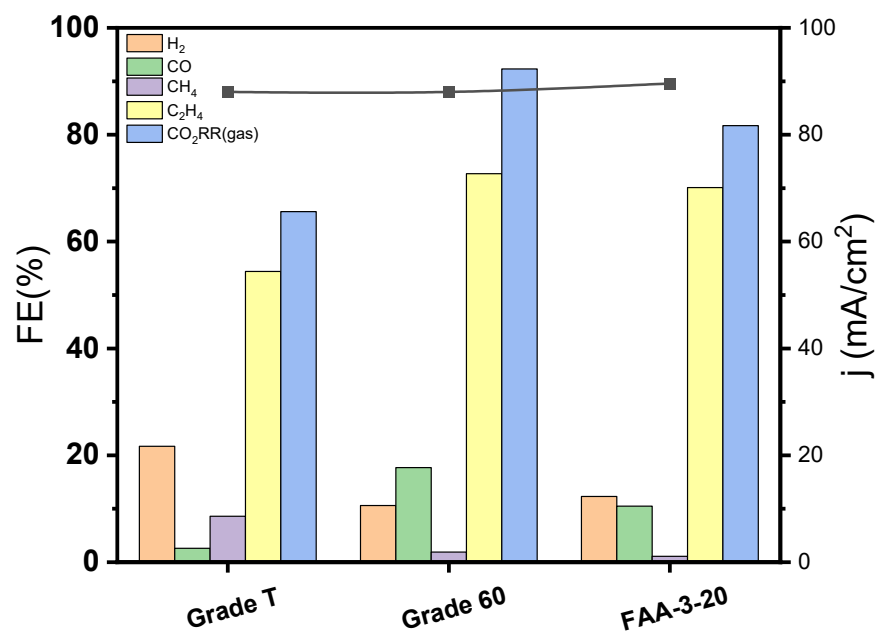

Figure 9. The Faraday efficiency of gas products and current density with different membranes. Operating parameter: Cell voltage $4.2 \mathrm{~V}, \mathrm{CO}_{2}$ gas flow rate of $10 \mathrm{sccm}$, anolyte flow rate of $10 \mathrm{sccm}$, and the channel type of series microchannel structure.

\subsubsection{Stability}

Figure 10 shows the stability test results. Three rounds of tests were conducted, and each test lasted $30 \mathrm{~min}$. The interval between the first test and the second test was $10 \mathrm{~min}$, and the interval between the second test and the third test was $12 \mathrm{~h}$. As shown in Figure 10a, the current was generally stable in the first test and the second test. However, in the third test, the current gradually decreased over time. As shown in Figure 10a, the FEs of $\mathrm{H}_{2}$, 
$\mathrm{CO}$, and $\mathrm{CH}_{4}$ showed no significant difference, and the FEs of $\mathrm{C}_{2} \mathrm{H}_{4}$ and $\mathrm{CO}_{2} \mathrm{RR}$ (gas) even increased. By contrast, the FE of $\mathrm{H}_{2}$ markedly increased, and the FEs of $\mathrm{C}_{2} \mathrm{H}_{4}$ and $\mathrm{CO}_{2} \mathrm{RR}$ (gas) decreased in the third round. One of the reasons may be attributed to the flooding phenomenon since the hydrophobicity of carbon paper would decrease and the three-phase interface will be damaged when it sets aside for a long time [28,29]. Further, the flooding phenomenon would cause catalysts to fall off from the carbon paper more easily. Parts of the catalysts were found to fall off from the carbon paper and be attached to the anion exchange membranes after the reaction. Figure $\mathrm{S} 4$ shows the XRD of CuNWs before and after the reaction. The intensity of the peak at $43.3^{\circ}$ decreased, and the peaks at $50.4^{\circ}$ and $74.1^{\circ}$ disappeared. The decreased intensity was ascribed to the catalyst shedding. No new peaks were found, which demonstrates that the crystal structure of CuNWs remained stable. It is reported that the low stability of $\mathrm{Cu}$-based GDE may originate from the degradation phenomenon [30]. An ICP test was performed to detect the concentrations of $\mathrm{Cu}$ and Ir in the anodic solution before and after the reaction (Table S3). The concentrations of both $\mathrm{Cu}$ and Ir increased as the reaction time increased, which demonstrates that both anode and cathode showed a degradation phenomenon. In addition, the voltage used in the experiment was relatively high. Carbon paper is easily damaged by high voltage and is susceptible to electrical wetting at high cell voltage [30,31].

On the one hand, continuous material science research is required to develop advanced anode and cathode with low overpotential to decrease the cell voltage. On the other hand, new gas diffusion electrodes other than carbon paper are urgently required, and polytetrafluoroethylene (PTFE)-based gas diffusion electrodes may be good alternatives. However, most of the reported PTFE-based gas diffusion electrodes are based on magnetron sputtering or ion sputtering technology. The combination of nano-synthesis technology and magnetron sputtering technology is expected to play a more considerable role.
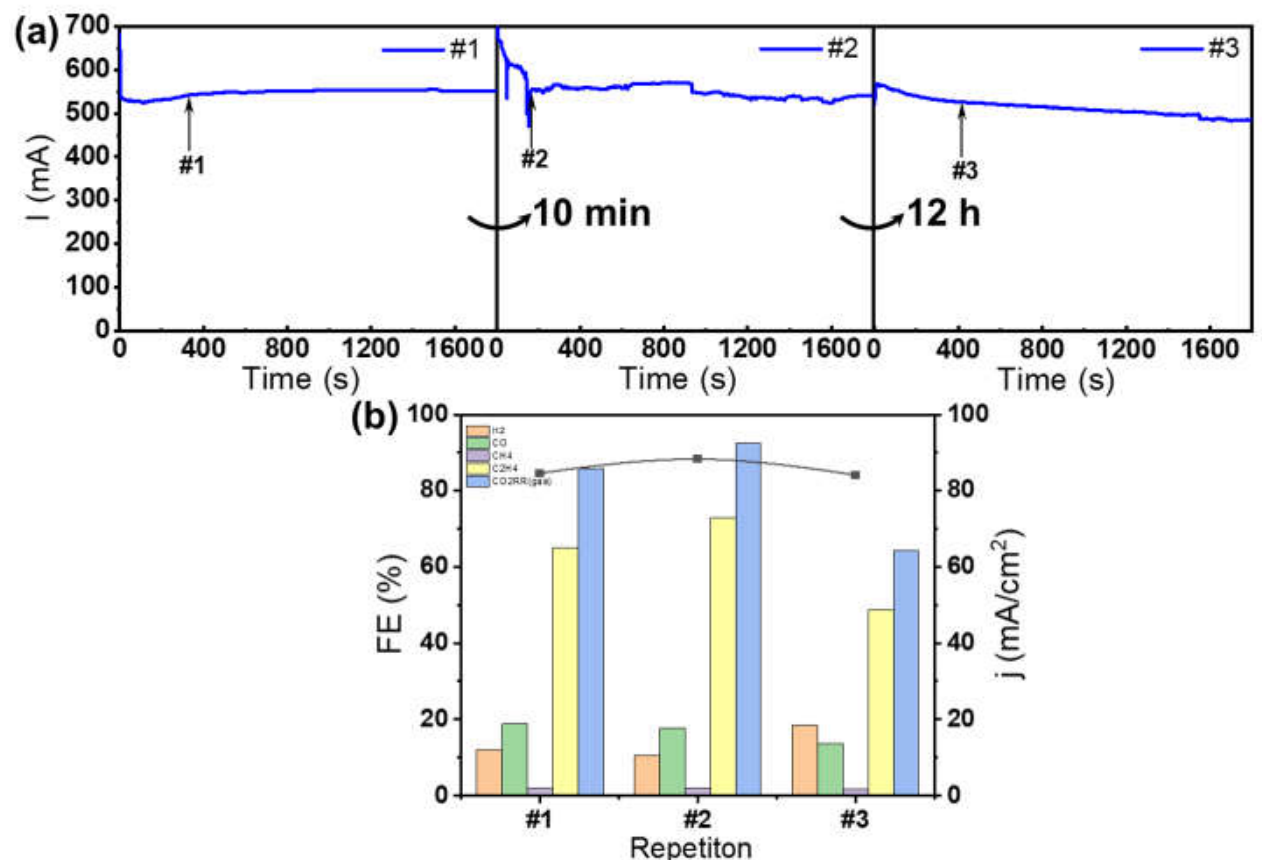

Figure 10. Stability test: (a) I-t curve; (b) the Faraday efficiency and current density. Operating parameter: Cell voltage $4.2 \mathrm{~V}, \mathrm{CO}_{2}$ gas flow rate of $10 \mathrm{sccm}$, anolyte flow rate of $10 \mathrm{sccm}$, the anion exchange membrane of Sustainion X37-50 Grade 60, and the channel type of series microchannel structure.

\subsection{6. $\mathrm{O}_{2}$ Production Capability}

The oxygen production capability of the membrane reactor is of vital importance for manned spacecraft in the extraterrestrial environment. We measured the oxygen production capability at the condition of cell voltage of $4.2 \mathrm{~V}, \mathrm{CO}_{2}$ gas flow rate of $10 \mathrm{sccm}$, an 
anolyte flow rate of $10 \mathrm{sccm}$, anion exchange membrane using Sustainion X37-50 Grade 60, and a parallel microchannel structure. The oxygen production capability was $111.7 \mathrm{mg} / \mathrm{h}$ ( $2.68 \mathrm{~g} /$ day), and the Faraday efficiency of oxygen was $80.8 \%$. To meet the oxygen requirement, the area of the membrane electrode should be $1900-1960 \mathrm{~cm}^{2}$.

\section{Materials and Methods}

\subsection{Materials and Electrode Preparation}

CuNWs were prepared according to the previous reference [32]. The catalyst ink was prepared by adding $20 \mathrm{mg} \mathrm{CuNWs}$ into a mixed solution of $3 \mathrm{~mL}$ cyclohexane and $70 \mu \mathrm{L}$ Nafion (DuPont D520, 5 wt\%, Suzhou Sinero Technology Co., Ltd, China), and then was ultrasonically treated for $60 \mathrm{~min}$ to form a homogeneous ink. The GDE was prepared by spraying the above ink with an airbrush on carbon paper (SIGRACET 29BC, Suzhou Sinero Technology Co., Ltd, China, $5 \mathrm{~cm} \times 5 \mathrm{~cm}$ ). Then, the above GDE was dried by an infrared heat lamp for about $20 \mathrm{~min}$. The catalyst-loading density was about $0.8 \mathrm{mg} / \mathrm{cm}^{2}$. Lastly, the GDE was cut to the desired size by using a paper knife.

The $\mathrm{IrO}_{2}$ based GDE was purchased from Dioxide Materials Inc, Boca Raton, FL, USA.

\subsection{Characterization Methods}

SEM images were obtained by field emission scanning electron microscopy (Helios G4 CX, Thermo Fisher Scientific, Waltham, MA, USA). TEM images were obtained by using a transmission electron microscope (Tecnai G2 F30, FEI, Hillsboro, OR, USA). XPS spectra were obtained via an X-ray photoelectron spectrometer (ESCALAB 250Xi, Thermo Fisher Scientific, Waltham, MA, USA); all binding energies were corrected according to the C1s peak at $284.8 \mathrm{eV}$. An X-ray diffractometer (D8 advance, $\lambda=0.154 \mathrm{~nm}$, Bruker, Billerica, MA, USA) was utilized to observe the XRD patterns. An ICP test was performed through ICP-MS (ICAP-MS-Qc, Thermo Fisher Scientific, Waltham, MA, USA).

\subsection{Performance Test}

Before the $\mathrm{CO}_{2}$ reduction experiments, the anion exchange membranes were activated in $1 \mathrm{M} \mathrm{KOH}$ and $0.2 \mathrm{M} \mathrm{KHCO}_{3}$, respectively. Then, the prepared cathode and $\mathrm{IrO}_{2}$ anode were attached to each side of the anion exchange membrane. Both cathode and anode geometric areas were $2.5 \mathrm{~cm} \times 2.5 \mathrm{~cm}$. Both the anode and cathode were sealed by the silica gel gasket. The assembled cell was conducted to detect the leakage rate under $0.5 \mathrm{MPa}$ Ar atmosphere.

The $\mathrm{CO}_{2}$ reduction experiments were performed under potentiostatic operation using a DC power source (B2902A, Keysight Technologies, USA). A DC voltage was supplied on the anodic and cathodic substrates (current collectors), in which the positive electrode was linked to the anode, and the negative one was linked to the cathode, respectively. Then, $0.2 \mathrm{M} \mathrm{KHCO}_{3}$ aqueous solution was introduced into the anode, and the aqueous solution flow rate was controlled, while $\mathrm{CO}_{2}(99.99 \%)$ was continuously purged into the gas channel through a mass flowmeter. After several minutes, until the I-t curve was smooth and steady, $0.25 \mathrm{~mL}$ gas products from the reaction were injected into and analyzed by a gas chromatograph (GC-2014C, Shimadzu, Kyoto, Japan), coupled with a thermal conductivity detector (TCD) and a flame ionization detector (FID). For tests at atmosphere conditions, the gas sampling from the soft bag was averaged over the previous time.

\section{Conclusions}

In this work, we designed an electrochemical membrane reactor at room temperature based on microfluidic control for the reduction of $\mathrm{CO}_{2}$ in extraterrestrial space. A microfluidic control technique was utilized to promote the gas-liquid interfacial phase separation under a microgravity environment. In this system, the highest Faraday efficiency (FE) of $\mathrm{C}_{2} \mathrm{H}_{4}$ was $72.7 \%$, with a current density of $88 \mathrm{~mA} / \mathrm{cm}^{2}$. The single-pass carbon efficiency (SPCE) of $\mathrm{CO}_{2}$ toward $\mathrm{C}_{2} \mathrm{H}_{4}$ and gas products were $4.64 \%$ and $11.61 \%$, respectively. The $\mathrm{CO}_{2}$ reduction performance was investigated under different operating conditions 
in detail including voltage, the flow rate of electrolyte and $\mathrm{CO}_{2}$, channel structure, and membrane, respectively. In addition, a microfluidic control technique was adopted to overcome the influence of the microgravity environment. The oxygen production capability was $111.7 \mathrm{mg} / \mathrm{h}$ (2.68 g/day). This work provides a possible technology path for $\mathrm{CO}_{2}$ utilization and $\mathrm{O}_{2}$ supply during the process of space exploration.

Supplementary Materials: Supporting Information is available online at https:/ /www.mdpi.com/ article/10.3390/catal12010003/s1, Figure S1: Diameter distributions of CuNWs. Figure S2: XPS of survey spectra of CuNWs. Figure S3: Typical (a) TCD and (b) FID chromatograms of cathodic gas products measured under the condition: $\mathrm{CO}_{2}$ gas flow rate of $10 \mathrm{sccm}$, anolyte flow rate of $10 \mathrm{sccm}$, the voltage of $4.2 \mathrm{~V}$, the anion exchange membrane of Sustainion X37-50 Grade 60, and the channel type of series microchannel structure. Table S1: The single-pass carbon efficiency (SPCE) of $\mathrm{CO}_{2}$ towards each product at $4.2 \mathrm{~V}$. Table S2: The energy efficiency $(\mathrm{EE})$ of $\mathrm{CO}_{2}$ towards $\mathrm{C}_{2} \mathrm{H}_{4}$ at $4.2 \mathrm{~V}$. Table S3: Concentrations of $\mathrm{Cu}$ and $\mathrm{Ir}$ in the anodic solution before and after the reaction.

Author Contributions: Conceptualization, methodology, visualization, writing-original draft preparation, D.F.; writing — original draft preparation, supervision, validation, investigation, funding acquisition, W.J.; formal analysis, writing-review and editing, C.Z.; L.L.; B.H., and J.S.; project administration, funding acquisition, W.Y. All authors have read and agreed to the published version of the manuscript.

Funding: This work was supported by the National Key Research and Development Program of China (2020YFA0710304), National Natural Science Foundation of China (22002185), Beijing, Natural Science Foundation (2204100), and Outstanding Young Talents Foundation of CAST.

Data Availability Statement: Not applicable.

Conflicts of Interest: The authors declare no conflict of interest.

\section{References}

1. Messerschmid, E.; Bertrand, R. Space Stations: Systems and Utilization; Springer Science \& Business Media: Berlin/Heidelberg, Germany, 2013.

2. Law, J.; Watkins, S.; Alexander, D. In-flight carbon dioxide exposures and related symptoms: Association, susceptibility, and operational implications. NASA Tech. Paper 2010, 216126, 2010.

3. Greenwood, Z.; Abney, M.; Stanley, C.; Brown, B.; Fox, E. State of NASA Oxygen Recovery. In Proceedings of the 48th International Conference on Environmental Systems, Albuquerque, NM, USA, 8-12 July 2018.

4. Hinterman, E.; Hoffman, J.A. Simulating oxygen production on Mars for the Mars Oxygen In-Situ Resource Utilization Experiment. Acta Astronaut. 2020, 170, 678-685. [CrossRef]

5. Hecht, M.; Hoffman, J.; Rapp, D.; McClean, J.; SooHoo, J.; Schaefer, R.; Aboobaker, A.; Mellstrom, J.; Hartvigsen, J.; Meyen, F. Mars Oxygen ISRU Experiment (MOXIE). Space Sci. Rev. 2021, 217, 1-76. [CrossRef]

6. Yang, L.; Zhang, C.; Yu, X.; Yao, Y.; Li, Z.; Wu, C.; Yao, W.; Zou, Z. Extraterrestrial artificial photosynthetic materials for in-situ resource utilization. Natl. Sci. Rev. 2021, 8, nwab104. [CrossRef]

7. Ma, D.; Jin, T.; Xie, K.; Huang, H. An overview of flow cell architectures design and optimization for electrochemical $\mathrm{CO}_{2}$ reduction. J. Mater. Chem. A 2021, 9, 20897-20918. [CrossRef]

8. O'Brien, C.P.; Miao, R.K.; Liu, S.; Xu, Y.; Lee, G.; Robb, A.; Huang, J.E.; Xie, K.; Bertens, K.; Gabardo, C.M. Single Pass CO 2 Conversion Exceeding 85\% in the Electrosynthesis of Multicarbon Products via Local $\mathrm{CO}_{2}$ Regeneration. ACS Energy Lett. 2021, 6 , 2952-2959. [CrossRef]

9. Gabardo, C.M.; O’Brien, C.P.; Edwards, J.P.; McCallum, C.; Xu, Y.; Dinh, C.-T.; Li, J.; Sargent, E.H.; Sinton, D. Continuous carbon dioxide electroreduction to concentrated multi-carbon products using a membrane electrode assembly. Joule 2019, 3, $2777-2791$. [CrossRef]

10. Dunfeng, G.; Pengfei, W.; Hefei, L.; Long, L.; Guoxiong, W.; Xinhe, B. Designing Electrolyzers for Electrocatalytic $\mathrm{CO}_{2}$ Reduction. Acta Phys.-Chim. Sin. 2021, 37, 2009021-0.

11. Luo, Y.; Zhang, K.; Li, Y.; Wang, Y. Valorizing carbon dioxide via electrochemical reduction on gas-diffusion electrodes. InfoMat 2021, 1-20. [CrossRef]

12. Lee, W.H.; Kim, K.; Lim, C.; Ko, Y.-J.; Hwang, Y.J.; Min, B.K.; Lee, U.; Oh, H.-S. New strategies for economically feasible CO 2 electroreduction using a porous membrane in zero-gap configuration. J. Mater. Chem. A 2021, 9, 16169-16177. [CrossRef]

13. Wei, P.; Li, H.; Lin, L.; Gao, D.; Zhang, X.; Gong, H.; Qing, G.; Cai, R.; Wang, G.; Bao, X. CO 2 electrolysis at industrial current densities using anion exchange membrane based electrolyzers. Sci. China Chem. 2020, 63, 1711-1715. [CrossRef]

14. Vennekoetter, J.-B.; Sengpiel, R.; Wessling, M. Beyond the catalyst: How electrode and reactor design determine the product spectrum during electrochemical $\mathrm{CO}_{2}$ reduction. Chem. Eng. J. 2019, 364, 89-101. [CrossRef] 
15. Matsushima, H.; Nishida, T.; Konishi, Y.; Fukunaka, Y.; Ito, Y.; Kuribayashi, K. Water electrolysis under microgravity: Part 1. Experimental technique. Electrochim. Acta 2003, 48, 4119-4125. [CrossRef]

16. Modestino, M.A.; Rivas, D.F.; Hashemi, S.M.H.; Gardeniers, J.G.E.; Psaltis, D. The potential for microfluidics in electrochemical energy systems. Energy Environ. Sci. 2016, 9, 3381-3391. [CrossRef]

17. Jiang, W.; Ruan, Q.; Xie, J.; Chen, X.; Zhu, Y.; Tang, J. Oxygen-doped carbon nitride aerogel: A self-supported photocatalyst for solar-to-chemical energy conversion. Appl. Catal. B Environ. 2018, 236, 428-435. [CrossRef]

18. Gu, Z.; Yang, N.; Han, P.; Kuang, M.; Mei, B.; Jiang, Z.; Zhong, J.; Li, L.; Zheng, G. Oxygen vacancy tuning toward efficient electrocatalytic $\mathrm{CO}_{2}$ reduction to $\mathrm{C}_{2} \mathrm{H}_{4}$. Small Methods 2019, 3, 1800449.

19. Li, M.; Ma, Y.; Chen, J.; Lawrence, R.; Luo, W.; Sacchi, M.; Jiang, W.; Yang, J. Residual Chlorine Induced Cationic Active Species on a Porous Copper Electrocatalyst for Highly Stable Electrochemical $\mathrm{CO}_{2}$ Reduction to $\mathrm{C}^{2+}$. Angew. Chem. 2021, 133, 11588-11594. [CrossRef]

20. Li, R.; Xu, J.; Zeng, R.; Pan, Q.; Tang, T.; Luo, W. Halides-assisted electrochemical synthesis of $\mathrm{Cu} / \mathrm{Cu} 2 \mathrm{O} / \mathrm{CuO}$ core-shell electrocatalyst for oxygen evolution reaction. J. Power Sources 2020, 457, 228058. [CrossRef]

21. Weekes, D.M.; Salvatore, D.A.; Reyes, A.; Huang, A.; Berlinguette, C.P. Electrolytic $\mathrm{CO}_{2}$ reduction in a flow cell. Accounts. Chem. Res. 2018, 51, 910-918. [CrossRef] [PubMed]

22. Xu, Y.; Edwards, J.P.; Liu, S.; Miao, R.K.; Huang, J.E.; Gabardo, C.M.; O’Brien, C.P.; Li, J.; Sargent, E.H.; Sinton, D. Self-cleaning $\mathrm{CO}_{2}$ reduction systems: Unsteady electrochemical forcing enables stability. ACS Energy Lett. 2021, 6, 809-815. [CrossRef]

23. Endrődi, B.; Samu, A.; Kecsenovity, E.; Halmágyi, T.; Sebők, D.; Janáky, C. Operando cathode activation with alkali metal cations for high current density operation of water-fed zero-gap carbon dioxide electrolysers. Nat. Energy 2021, 6, 439-448. [CrossRef]

24. Huang, J.E.; Li, F.; Ozden, A.; Rasouli, A.S.; de Arquer, F.P.G.; Liu, S.; Zhang, S.; Luo, M.; Wang, X.; Lum, Y. CO 2 electrolysis to multicarbon products in strong acid. Science 2021, 372, 1074-1078. [CrossRef] [PubMed]

25. Xing, Z.; Hu, L.; Ripatti, D.S.; Hu, X.; Feng, X. Enhancing carbon dioxide gas-diffusion electrolysis by creating a hydrophobic catalyst microenvironment. Nat. Commun. 2021, 12,1-11. [CrossRef]

26. Endrődi, B.; Kecsenovity, E.; Samu, A.; Halmágyi, T.; Rojas-Carbonell, S.; Wang, L.; Yan, Y.; Janáky, C. High carbonate ion conductance of a robust PiperION membrane allows industrial current density and conversion in a zero-gap carbon dioxide electrolyzer cell. Energ. Environ. Sci. 2020, 13, 4098-4105. [CrossRef]

27. Salvatore, D.A.; Gabardo, C.M.; Reyes, A.; O’Brien, C.P.; Holdcroft, S.; Pintauro, P.; Bahar, B.; Hickner, M.; Bae, C.; Sinton, D. Designing anion exchange membranes for $\mathrm{CO}_{2}$ electrolysers. Nat. Energy 2021, 6, 339-348. [CrossRef]

28. Shi, R.; Guo, J.; Zhang, X.; Waterhouse, G.I.; Han, Z.; Zhao, Y.; Shang, L.; Zhou, C.; Jiang, L.; Zhang, T. Efficient wettabilitycontrolled electroreduction of $\mathrm{CO}_{2}$ to $\mathrm{CO}$ at $\mathrm{Au} / \mathrm{C}$ interfaces. Nat. Commun. 2020,11, 1-10. [CrossRef] [PubMed]

29. Chen, S.; Li, W.-H.; Jiang, W.; Yang, J.; Zhu, J.; Wang, L.; Ou, H.; Zhuang, Z.; Chen, M.; Sun, X. MOF Encapsulating N-Heterocyclic Carbene-Ligated Copper Single-Atom Site Catalyst towards Efficient Methane Electrosynthesis. Angew. Chem. Int. Edit. 2021. [CrossRef]

30. Popović, S.; Smiljanić, M.; Jovanovič, P.; Vavra, J.; Buonsanti, R.; Hodnik, N. Stability and Degradation Mechanisms of CopperBased Catalysts for Electrochemical $\mathrm{CO}_{2}$ Reduction. Angew. Chem. Int. Edit. 2020, 59, 14736-14746. [CrossRef] [PubMed]

31. Yang, K.; Kas, R.; Smith, W.A.; Burdyny, T. Role of the carbon-based gas diffusion layer on flooding in a gas diffusion electrode cell for electrochemical $\mathrm{CO}_{2}$ reduction. ACS Energy Lett. 2020, 6, 33-40. [CrossRef]

32. Choi, C.; Kwon, S.; Cheng, T.; Xu, M.; Tieu, P.; Lee, C.; Cai, J.; Lee, H.M.; Pan, X.; Duan, X. Highly active and stable stepped Cu surface for enhanced electrochemical $\mathrm{CO}_{2}$ reduction to $\mathrm{C}_{2} \mathrm{H}_{4}$. Nat. Catal. 2020, 3, 804-812. [CrossRef] 